\title{
Array-based identification of common DNA methylation alterations in ulcerative colitis
}

\author{
KEI KOIZUMI $^{1 *}$, SERGIO ALONSO $^{2 *}$, YUICHIRO MIYAKI $^{1}$, SHINICHIRO OKADA $^{3}$, HIROYUKI OGURA $^{1}$, \\ NORIHIKO SHIIYA ${ }^{1}$, FUMIO KONISHI ${ }^{3}$, TOSHIKI TAYA ${ }^{4}$, MANUEL PERUCHO ${ }^{2,5,6}$ and KOICHI SUZUKI ${ }^{3}$
}

\author{
${ }^{1}$ First Department of Surgery, Hamamatsu University School of Medicine, 1-20-1 Handa-yama, Higashi-ku, Hamamatsu, \\ Shizuoka 431-3192, Japan; ${ }^{2}$ Institute of Predictive and Personalized Medicine of Cancer (IMPPC), Carretera de Can Ruti S/N, \\ 08916 Badalona, Spain; ${ }^{3}$ Department of Surgery, Saitama Medical Center, Jichi Medical University, 1-847 Amanuma-cho, \\ Omiya-ku, Saitama 330-8503; ${ }^{4}$ Agilent Technologies, 9-1 Takakura-cho, Hachioji, Tokyo 192-8510, Japan; \\ ${ }^{5}$ Sanford-Burnham Medical Research Institute, Tumor Development Program, 10901 North Torrey Pines Road, \\ La Jolla, CA 92037, USA; ${ }^{6}$ Catalan Institution for Research and Advanced Studies (ICREA), \\ Pg. Lluís Companys 23, 08010 Barcelona, Spain
}

Received September 30, 2011; Accepted November 2, 2011

DOI: 10.3892/ijo.2011.1283

\begin{abstract}
Patients with long-standing ulcerative colitis (UC) have higher risk of developing colorectal cancer. Albeit the causes remain to be understood, epigenetic alterations have been suggested to play a role in the long-term cancer risk of these patients. In this work, we developed a novel microarray platform based on methylation-sensitive amplified fragment length polymorphism (MS-AFLP) DNA fingerprinting. The over 10,000 NotI sites of the human genome were used to generate synthetic primers covering these loci that are equally distributed into $\mathrm{CpG}$ rich regions (promoters and $\mathrm{CpG}$ islands) and outside the $\mathrm{CpG}$ islands, providing a panoramic view of the methylation alterations in the genome. The arrays were first tested using the colon cancer cell line CW-2 showing the reproducibility and sensitivity of the approach. We next investigated DNA methylation alterations in the colonic mucosa of $14 \mathrm{UC}$ patients. We identified epigenetic alterations affecting genes putatively involved in UC disease, and in susceptibility to develop colorectal cancer. There was a strong concordance of methylation alterations (both hypermethylation and hypomethylation) shared by the cancer cells of the CW-2 cell
\end{abstract}

Correspondence to: Dr Koichi Suzuki, Department of Surgery, Saitama Medical Center, Jichi Medical University, 1-847 Amanumacho, Omiya-ku, Saitama-shi, Saitama 330-8503, Japan

E-mail:ksuzbnhm@omiya.jichi.ac.jp

*Contributed equally

Abbreviations: UC, ulcerative colitis; UCM, non-neoplastic UC mucosa; methylation sensitive amplified fragment length polymorphism, MS-AFLP; OR, odds ratio; CI, confidence interval

Key words: ulcerative colitis associated carcinogenesis, methylation profiling, field cancerization, methylation sensitive amplified fragment length polymorphism, microarray, MS-AFLP line and the non-cancer UC samples. To the best of our knowledge, this work defines the first high-throughput aberrant DNA methylation profiles of the colonic mucosa of UC patients. These epigenetic profiles provide novel and relevant knowledge on the molecular alterations associated to the UC pathology. Some of the detected alterations could be exploited as cancer risk predictors underlying a field defect for cancerization in UC-associated carcinogenesis.

\section{Introduction}

Ulcerative colitis (UC) is a chronic disease characterized by inflammation of the mucosa and submucosa of the large intestine. The duration and extent to which a patient suffers from UC are directly proportional to a propensity for colorectal cancer $(1,2)$. Ulcerative colitis patients have elevated risk of colorectal cancer. This risk has been estimated to be $2 \%$ after 10 years, $8 \%$ after 20 years and $18 \%$ after 30 years of disease (3). Unlike sporadic colorectal cancers that typically follow the adenoma-carcinoma pathway, UC-associated colorectal tumors progress from areas of dysplastic mucosa, following what it has been termed the dysplasia-carcinoma pathway. These tumors typically develop as flat lesions, which in many instances are difficult to detect, especially in areas of active inflammation (4-8). Owing to improvements in UC treatment this disease is rarely lethal per se, and the associated mortality is largely determined by the incidence of colorectal cancer. As of today, very little is known about the molecular basis of the UC-associated colorectal cancer. This highlights the urgent need to determine the early genetic and epigenetic alterations germane to the UC-associated carcinogenesis (9). Discerning the mechanisms underlying UC-associated colorectal cancer will facilitate the identification of markers for predisposition of the UC-associated carcinogenesis, which in turn might improve the prognosis and treatment of UC patients.

In several diseases characterized by chronic inflammation, such as chronic hepatitis and Helicobacter pylori infection 
chronic gastritis, aberrant DNA methylation of promoter-associated $\mathrm{CpG}$ islands is associated with transcriptional inactivation of tumor suppressor genes (10). In addition, aberrant DNA methylation has been observed not only in cancer tissues but also in tissues that appear to be histologically normal (11-13), suggesting that some cancers arise from regions containing certain epigenetic alterations that may be shared with an accompanying cancer. This phenomenon is exemplified by the 'field cancerization' caused by carcinogen exposure (14). Molecular alterations such as p16 (15) and p14 hypermethylation (16), were more frequently observed in non-neoplastic epithelium of UC patients with neoplasia than in those without neoplasia, suggesting that these molecular alterations may be exploited as markers for identifying individuals with UC at increased risk of neoplasia. Chronic inflammation has been reported to associate with high levels of $\mathrm{CpG}$ island hypermethylation, perhaps as a result of increased cell turnover, and that age-related methylation marks (and may lead to) the field defect that reflects acquired predisposition to colorectal neoplasia (17). Fujii et al, reported that ER gene methylation may be potentially useful for identifying individuals at increased risk of neoplasia among patients with long-standing and extensive UC (18). In addition, global DNA hypomethylation in the rectal mucosa of patients with UC has been proposed to be the result of the increased proliferative activity triggered by the active inflammation, and that this epigenetic change might predispose these individuals to develop colorectal neoplasm (19). The genomic extent of methylation alterations in UC mucosa, however, remains to be accurately defined. In this regard, genome wide analyses of methylation alterations provide an effective strategy to elucidate the influence of epigenetic alterations on field cancerization.

Methylation sensitive amplified fragment length polymorphism (MS-AFLP) is a fingerprinting technique developed by Yamamoto et al as a tool to analyze DNA methylation in hundreds of loci simultaneously $(20,21)$. MS-AFLP is based on the differential PCR amplification of methylated vs. unmethylated NotI sites. We employed this technique to demonstrate that the accumulation of DNA methylation alterations in human colorectal and gastric cancers occurs in a gradual fashion (22), and that this accumulation associates with aging and precedes genomic damage (23). More recently, we developed a fluorescence-labeled MS-AFLP technique for the detection of hyper- and hypomethylation alterations using a fluorescencedetecting electrophoresis apparatus (24). One advantage of the MS-AFLP over similar approaches is that approximately half (44\%) of the NotI recognition sites are located in or adjacent to $\mathrm{CpG}$ islands, while the rest (56\%) are located outside the $\mathrm{CpG}$ islands. This distribution enables to detect both DNA hypermethylation, generally occurring closer to $\mathrm{CpG}$ islands, and DNA hypomethylation, generally affecting repetitive elements and single copy loci outside CpG islands (25). Thus, MS-AFLP provides unbiased insight into the complex picture of hypermethylation and hypomethylation alterations, both of which are known to be associated with cancer (26). In its original format, however, MS-AFLP was limited by the number of bands than can be resolved in a single electrophoretic gel, typically less than 100 . This limitation could be partly overcome by employing several primer combinations that amplify different subsets of the NotI-MseI fragment, but this solution is still insufficient to analyze the nearly 10,000 NotI sites of the human genome. A previous attempt to increase its throughput by applying MS-AFLP to a DNA microarray hybridization demonstrated the feasibility of the approach (27). This methodology, however, required the cloning and sequencing of individual MS-AFLP fragments before printing them onto the arrays, two very labor-intensive steps that represented an important hurdle for scaling up the throughput of the MS-AFLP microarrays.

In this study, we have designed a novel MS-AFLP array-based platform containing probes consisting of 60-mer-oligonucleotides, which cover the sequences adjacent to all the NotI sites identified in the human genome sequence. Using this platform, we have identified methylation alterations in non-neoplastic UC epithelia. Our results describe for the first time the genome-wide methylation profile of UC mucosa samples, and provides clues for the increased risk for developing colorectal cancer.

\section{Materials and methods}

Cell culture, patients and tissues. The human colon cancer cell line CW-2 (RCB0778) was provided by the RIKEN Cell Bank (RCB, Tsukuba,Japan). CW-2 cells were cultured in Roswell Park Memorial Institute 1640 (RPMI-1640) medium supplemented with $10 \%$ fetal bovine serum (FBS), 10,000 U/ml penicillin G, $10 \mathrm{mg} / \mathrm{ml}$ streptomycin sulfate and $25 \mu \mathrm{g} / \mathrm{ml}$ amphotericin B. The cells were maintained at $37^{\circ} \mathrm{C}$ in a humidified incubator with $5 \% \mathrm{CO}_{2}$.

Fourteen non-neoplastic UC epithelia biopsies (UCM) were obtained from patients who had undergone surgery at Jichi Medical University Saitama Medical Center and Jichi Medical University hospital. In addition, 11 normal colon mucosal tissues from healthy volunteers were collected and used as controls. The study design was approved by the Institutional Review Board (IRB) of Hamamatsu University School of Medicine and Jichi Medical University.

Design of the methylation sensitive amplified fragment array. To design the MS-AFLP array, we retrieved all the 80-bp upstream and downstream sequences adjacent to every one of the 9,654 NotI sites previously mapped on the Build 36 of the human genome sequence obtained from the NCBI. These sequences were employed to design 19,308 60-mer microarray probes using OligoArray 2.0, a program that designs specific oligonucleotides at the genomic scale (28). This process generated a set of 19,308 probes, two probes (one upstream and one downstream) per every NotI site in the human genome sequence. Using the same process, 2,200 additional methylation-insensitive probes within MseI-MseI fragments were designed to control for copy number alterations. All these oligonucleotides were synthesized in duplicate onto array slides by an ink-jet oligonucleotide synthesizer apparatus at Agilent Technologies. The MS-AFLP array comprises a total number of 43,016 synthesized probes: $19,308 \times 2$ methylation sensitive probes, plus 2,200x2 methylation-insensitive probes, and approximately two thousand additional features required for the array scanning and quality control. NotI sites are associated to DNA regions with a high GC content, which are also rich in repetitive elements. Mapped NotI sites $(8.8 \%)$ occur within or adjacent to repetitive sequences, in particular AluY elements. Hence, some NotI-associated probes are unavoidably located inside repetitive elements. To identify those probes complementary to repetitive elements, every probe 
was re-mapped on the entire human genome sequence allowing up to one mismatch. Of the 19,308 probes, 18,086 (93.7\%) were unique in the genome while 1222 (6.3\%) mapped in two or more locations (896 probes mapping in 2-10 loci, 130 probes mapping in 11-100 loci, 110 probes mapping in 101-1,000 loci, 80 probes mapping in 1,001-10,000 loci, and 6 probes mapping in $>10,000$ loci). Therefore, the MS-AFLP array design allows the determination of methylation alterations in unique loci, moderately repetitive DNA elements and highly repetitive DNA elements. The MS-AFLP arrays employed in this study were printed at Agilent Technologies facilities at Hachioji (Tokyo 192-8510, Japan), under a collaborative arrangement.

Preparation, labeling and hybridization of DNA samples for MS-AFLP arrays. Genomic DNA was isolated by QIAamp DNA Mini Kit (Qiagen, Hilden, Germany). The initial steps of the MS-AFLP were performed as previously described (20). Briefly, $1 \mu \mathrm{g}$ of genomic DNA was digested overnight with $5 \mathrm{U}$ of methylation-sensitive NotI (Promega, Madison, WI, USA) and 2 U of methylation-insensitive MseI (NE Biolabs, Beverly, MA, USA) at $37^{\circ} \mathrm{C}$. Two pairs of oligonucleotides were annealed overnight at $37^{\circ} \mathrm{C}$ to generate $\mathrm{NotI}$ (5'-CTCGTAGACTGCGTAGG-3' and 5'-GGCCCCTACGCAGTCTAC-3') and $\mathrm{Mse}$ I (5'-GACGATG AGTCCTGAG-3' and 5'-TACTCAGGACTCAT-3') specific adaptors. The digested DNA was ligated to $1.25 \mu \mathrm{l}$ each of $5 \mathrm{pmol} / \mu \mathrm{l}$ NotI and $50 \mathrm{pmol} / \mu \mathrm{l}$ MseI adaptor using $1 \mathrm{U}$ of T4 DNA ligase (Promega) overnight at $16^{\circ} \mathrm{C}$. The adaptorligated template DNA was amplified by PCR using NotI primer (5'-GACTGCGTAGGGGCCGCG-3') and MseI primer (5'-GATGAGTCCTGAGTAA-3'). The PCR mixture consisted of $6 \mathrm{ng}$ of $N o t \mathrm{I}$ primer, $30 \mathrm{ng}$ of $M s e \mathrm{I}$ primer, $0.25 \mathrm{mM} \mathrm{dNTP}$, and 1.5 U of AmpliTaq DNA polymerase (Applied Biosystems, Foster City, CA, USA) in a final volume of $20 \mu 1$. The PCR started at $72^{\circ} \mathrm{C}$ for $30 \mathrm{sec}$ and $94^{\circ} \mathrm{C}$ for $30 \mathrm{sec}$, followed by 35 cycles of $94^{\circ} \mathrm{C}$ for $30 \mathrm{sec}, 52^{\circ} \mathrm{C}$ for $30 \mathrm{sec}$, and $72^{\circ} \mathrm{C}$ for $2 \mathrm{~min}$. The final extension was performed for $10 \mathrm{~min}$ at $72^{\circ} \mathrm{C}$. The reactions were then kept at $10^{\circ} \mathrm{C}$ until the amplified DNA fragments were isolated using a QIAPCR Clean-up kit (Qiagen). DNA was eluted into $50 \mu 1$ of elution buffer.

Prior to hybridization on the MS-AFLP arrays, the DNA samples were labeled as previously described (27). Briefly, fluorescently labeled fragments were prepared using the Bioprime labeling system (Invitrogen). Each sample of PCR-amplified DNA $(50 \mathrm{ng} / 2.5 \mu \mathrm{l})$ was mixed with $5 \mu \mathrm{l}$ of water and $5 \mu \mathrm{l}$ of random primer mix solution. The mixtures were boiled at $100^{\circ} \mathrm{C}$ for $2 \mathrm{~min}$, quickly placed on ice for $1 \mathrm{~min}$, and briefly centrifuged for $10 \mathrm{sec}$. Then $1 \mu \mathrm{l}$ of either CY5 mix solution $(1.56 \mathrm{mM}$ each of dGTP, dATP and dTTP, $0.22 \mathrm{mM} \mathrm{dCTP}$, and $0.11 \mathrm{mM}$ Fluorolink CY5-dCTP) or CY3 mix solution (1.56 mM each of dGTP, dATP, and dTTP, $0.22 \mathrm{mM} \mathrm{dCTP}$, and $0.11 \mathrm{mM}$ Fluorolink CY3-dCTP) was added. Fluorolink CY5-dCTP and CY3-dCTP were purchased from Amersham-Pharmacia. Klenow fragment of $E$. coli DNA polymerase was then added to a final concentration of $0.8 \mathrm{U}$ per $\mu 1$. The mixtures were incubated at $37^{\circ} \mathrm{C}$ for $1 \mathrm{~h}$ before adding $2 \mu \mathrm{l}$ of stop solution (0.5 M EDTA) to terminate the reaction. The CY5 and CY3 fluorescently labeled DNA fragments were separated from the unincorporated dNTPs by filtration through Microcon YM-30 columns (Millipore, Bedford, MA, USA). Each sample was reconstituted with 1X TE ( $\mathrm{pH}$ 8.0) to a final volume of 37 and $2 \mu \mathrm{l}$ of each sample was taken to determine the yield of labeled genomic DNA and the specific activity after labeling and clean-up. Exposure of samples to light was minimized during all experimental procedures.

The Cy3 and Cy5 labeled DNA samples were mixed in a siliconized tube with $70 \mu \mathrm{l}$ of Agilent $2 \mathrm{X}$ Hi-RPM buffer (Agilent, Santa Clara, CA, USA). The mix was heated at $95^{\circ} \mathrm{C}$ for $3 \mathrm{~min}$ and centrifuged at $6000 \mathrm{x} \mathrm{g}$ for $1 \mathrm{~min}$ to collect the sample at the bottom of the tube. Hybridization sample mixture $(110 \mu \mathrm{l})$ was applied slowly to the gasket slide into the Agilent SureHyb chamber base. Then, one microarray slide was placed onto the gasket slide, with the active side facing down. The SureHyb chamber was covered onto the slides, and the clamp assembly was slid onto both pieces. The assembled slide chamber was placed in a rotator rack inside a hybridization oven and rotated at $20 \mathrm{rpm}$ and hybridized at $65^{\circ} \mathrm{C}$ for $40 \mathrm{~h}$. After hybridization, array slides were washed with Oligo aCGH wash buffer 1 at room temperature for $5 \mathrm{~min}$ and Oligo aCGH wash buffer 2 at $37^{\circ} \mathrm{C}$ for $1 \mathrm{~min}$. To prevent $\mathrm{Cy} 5$ degradation by ozone, the slides were washed with acetonitrile for $30 \mathrm{sec}$ and then with stabilization and drying solution for $30 \mathrm{sec}$. The arrays were scanned using an Agilent G2565BA DNA Microarray Scanner.

MS-AFLP array data analysis. After scanning, data extraction was conducted using the Feature Extraction software version A.10.5.1.1 (Agilent Technologies). GeneSpring version 10 (Agilent Technologies) was used to export the array data. For the MS-AFLP array data analysis, an ad hoc pipeline was developed in R (29). The background corrected signals were used to calculate the $\log 2$ ratio of the CY5 vs CY3 channel for every array feature. The $\log 2$ ratios were subsequently normalized by LOWESS method (locally weighted scatterplot smoothing), using the information from all the features in the array. Then, the normalized $\log 2$ ratios from the 19,308 methylation-sensitive probes were extracted from the dataset. Since these probes are synthesized in duplicate in the array, two independent $\log 2$ ratio values were obtained for each probe. These values were combined into a single value by calculating their weighted mean, where the weights were given by the total intensity of the replicates in both the CY3 and CY5 channels. Finally, the probes within the $30 \%$ lowest intensity in both the CY3 and CY5 channels in both replicates, likely representing cross-hybridization noise, were excluded from the subsequent analyses. The thresholds for hypermethylation and hypomethylation were set at $\log 2$ ratio $<-1$ and $\log 2$ ratio $>1$.

Bisulfite sequencing. Bisulfite sequencing was performed as previously described (30). Genomic DNA was modified with EpiTect Bisulfite $\mathrm{Kit}^{\mathrm{TM}}$ (Qiagen). Bisulfite-modified DNA was analyzed by PCR with primers specifically designed to amplify the NotI-containing products of interest. The primers and annealing temperature for the bisulfite sequencing were: spot a (NotI site no. 5391, primers 5'-TGTTATAGGGATGGA TTTTGTTAT-3' and 5'-CCACCCCTATATCATACCCT-3', annealing temperature: $56^{\circ} \mathrm{C}$ ); spot b (NotI site no. 2627 , primers 5'-GGTGGTTTGTTTTTTTGAAGA-3' and 5'-AACCTATAT CAAAACACCCCC-3', annealing temperature $50^{\circ} \mathrm{C}$ ); spot c (NotI site no. 6105, primers 5'-GAGTGATTGAATTAAGA AGAGTAAAA-3' and 5'-AAACTCAAACCCAATTAATT AAA-3', annealing temperature $46^{\circ} \mathrm{C}$ ); spot d (NotI site no. 374, primers 5'-TGTGTTAATATTTGGGGGTAGAG-3' and 
5'-TACTTCTACCCTAACCTCCCCT-3', annealing temperature $53^{\circ} \mathrm{C}$ ); spot e (NotI site no. 563, primers $5^{\prime}-\mathrm{GTG}$ TTTTAGGAGGATTTGGG-3' and 5'-AAAAAATACCCC TATCTCACCTC-3', annealing temperature $51^{\circ} \mathrm{C}$ ); and spot $\mathrm{f}$ (NotI site no. 3511, primers 5'-GTTTTTATTTGAGGGGGA ATG-3' and 5'-TACTCTTAACCTAACTCACCCCC-3', annealing temperature $51^{\circ} \mathrm{C}$ ). PCR amplifications were carried out in $20 \mu 1$ reaction mixtures containing $1 \mathrm{X}$ PCR buffer, 0.25 mM (each) dNTP mix, $0.025 \mathrm{U} / \mu 1$ HotStarTaq Plus DNA Polymerase (Qiagen) and $0.5 \mu \mathrm{M}$ each primer. The PCR conditions were $95^{\circ} \mathrm{C}$ for $5 \mathrm{~min}$, followed by 38 cycles of $95^{\circ} \mathrm{C}$ for $45 \mathrm{sec}$, then $45 \mathrm{sec}$ at the specific annealing temperature, $72^{\circ} \mathrm{C}$ for $1 \mathrm{~min}$, and then $72^{\circ} \mathrm{C}$ for $10 \mathrm{~min}$. PCR products were purified by EXOSAP-IT (USB Corp., Cleveland, OH, USA), and cloned into the pGEM-T Easy Vector (Promega). Recombinant plasmids were sequenced with an ABI PRISM 3100 Genetic Analyzer (Applied Biosystems) using SP6 (5'-TATTTAGGTGACACTATAG-3') and T7 (5'-TAA TACGACTCACTATAGGG-3') primers. The methylation status of each $\mathrm{CpG}$ site was determined by sequencing, as unmethylated cytosines are converted into thymines after the bisulfite treatment and PCR amplification, whereas methylated cytosines remain unaltered.

Statistical analysis. Statistical analyses were performed using the R statistical environment (29). Fisher's exact was used to examine associations between two categorical variables. Continuous variable comparisons between two groups were performed with the Student's t-test for those variables following a normal distribution, or with the non-parametric Mann-Whitney-Wilcoxon test for those variables that do not follow a normal distribution. Normality was assessed using the Shapiro-Wilk test. The level of statistical significance was set at $\mathrm{P}<0.01$, unless otherwise specified. Holm's multihypothesis testing correction was applied when appropriate (31). Hierarchical analysis and clustering analysis were performed using $\mathrm{MeV}$ (32). Gene category enrichment analyses were performed using DAVID $(33,34)$, which employs a more robust variation of the Fisher's exact test, termed EASE score (35). To account for the bias due to the partial gene representation in the MS-AFLP array, all the gene enrichment analyses were performed using the list of the genes present in the array as a background, instead of the total number of genes in the human genome.

\section{Results}

Set-up and testing the MS-AFLP array. To estimate the falsepositive rate of the MS-AFLP array we performed a self-self hybridization experiment using a mixture of DNAs obtained from the colonic mucosa of 11 healthy volunteers (see Materials and methods). This mixture of DNAs was used as reference sample in all the subsequent MS-AFLP arrays presented in this study. The results are shown in the scatter plot of Fig. 1a. In this plot, the logarithmic $\mathrm{x}$-axis and $\mathrm{y}$-axis represent the average signal in the Cy3 and Cy5 channels, respectively. The no-change line (log2 ratio $=0$ ) is in solid black. The diagonal dashed lines indicate the alteration calling thresholds, set at $\log 2$ ratio $>1$ for hypomethylation and $\log 2$ ratio $<-1$ for hypermethylation. According to the self-self hybridization experiment, the MS-AFLP array exhibited a $0.12 \%$ of false positives mostly in the low-intensity subset of probes, more susceptible to spurious fluctuations due to probe cross-hybridization. Applying a very stringent floor filter excluding the $30 \%$ lowest-intensity probes, the false positive rate was reduced to $<0.015 \%$. This filter was applied by default in all subsequent MS-AFLP array analyses.

The colon cancer cell line CW-2 was selected to determine the capabilities of the array-based MS-AFLP to detect DNA methylation alterations. CW-2 is a colorectal cancer cell line derived from a 60 -year-old female patient with lymph node metastases. The cells display microsatellite instability (MSI) due to an inactivating frameshift mutation in $h M L H I$. This alteration is fixed in homozygosis due to copy neutral $\mathrm{LOH}$ affecting the $62-\mathrm{Mb}$ distal region of the $3 \mathrm{p}$ chromosome, where $h M L H 1$ is located (data from The Cancer Genome Project of The Wellcome Trust Sanger Institute). Except for the loss of a $13-\mathrm{Mb}$ region of chromosome $\mathrm{X}, \mathrm{CW}-2$ cells harbor very few copy number alterations (CNAs), and they are mostly diploid with $84 \%$ of cells harboring a normal content of 46 chromosomes (information from the RIKEN BioResource Center).

The result of the MS-AFLP array analysis of CW-2 DNA relative to a pooled sample of normal colon tissue DNAs is shown in Fig. 1b. To validate the methylation changes detected by the MS-AFLP array, we selected six probes representing two hypomethylated NotI sites (a and b), two non-altered NotI sites (c and d) and two hypermethylated NotI sites (e and f). These loci were analyzed by bisulfite genomic sequencing, the current gold standard technique to analyze DNA methylation, using the primers indicated in Materials and methods. The results obtained by bisulfite sequencing (Fig. 1c) confirmed the results from the MS-AFLP array in all the analyzed loci, demonstrating the capability of the MS-AFLP array to detect DNA methylation alterations. In addition, no association between the chromosomal location of the DNA methylation alterations and the copy number variations reported in CW-2 was observed (data not shown), which further supports the validity of this platform to accurately detect somatic epigenetic changes even within chromosomal regions that had undergone moderate copy number alterations.

The MS-AFLP array analysis of the genome of CW-2 DNA revealed 500 probes $(3.75 \%)$ with $\log 2$ ratio below the hypermethylation threshold, and 129 probes $(0.95 \%)$ with $\log 2$ ratio above the hypomethylation threshold (Fig. 1b). Since this cell line is derived from a female patient, the data from the $\mathrm{Y}$ chromosome probes was removed from the analysis. Due to design strategy constrains, the MS-AFLP array contains 94 probes with mononucleotide repeats of 9 or more nucleotides (polyN). Shortenings and expansions of mononucleotide repeats are the archetypical feature of the MSI phenotype resulting from defects in the mismatch repair mechanisms (36). Since CW-2 is an MSI cell line, we investigated whether the polyN-containing probes exhibited a particular behavior. Out of the 94 probes with polyN sequences, 8 where excluded due to low intensity in both the $\mathrm{Cy} 3$ (reference sample) and $\mathrm{Cy} 5$ (CW-2 sample) channels. Of the remaining 86 probes, 17 (19.8\%) exhibited a $\log 2$ ratio below the hypermethylation threshold (i.e., significantly hypermethylated), a much higher frequency than that of probes without polyN $(483 / 13015,3.7 \%)$. None of the polyN-containing probes exhibited $\log 2$ ratios above the hypomethylation threshold (i.e., significantly hypomethylated). Hence, there was 

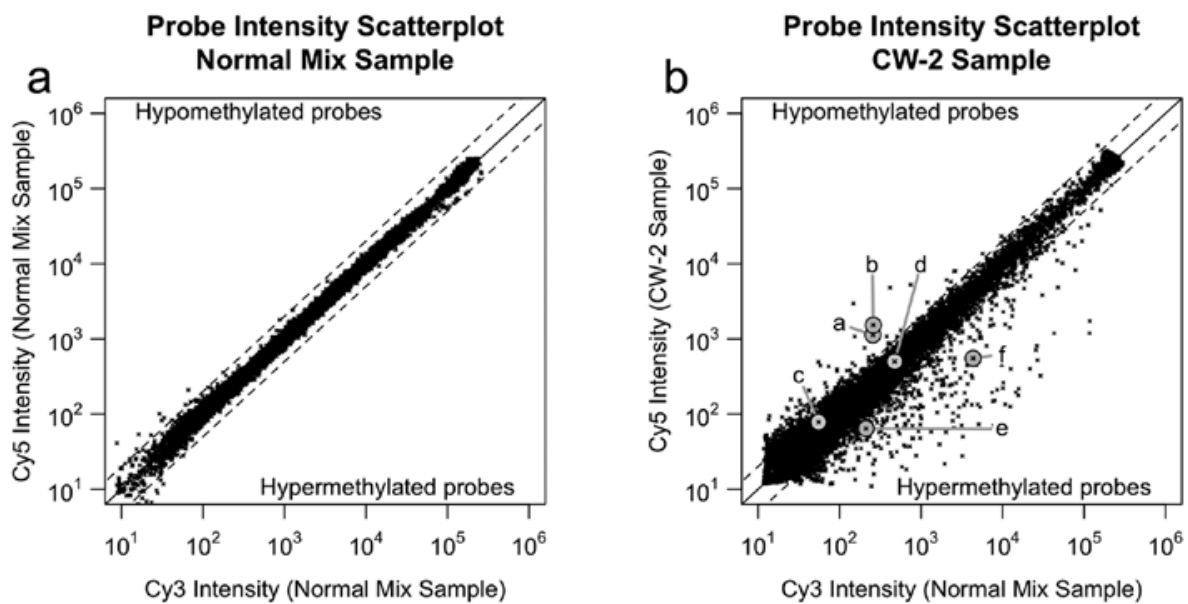

C

Bisulfite sequencing

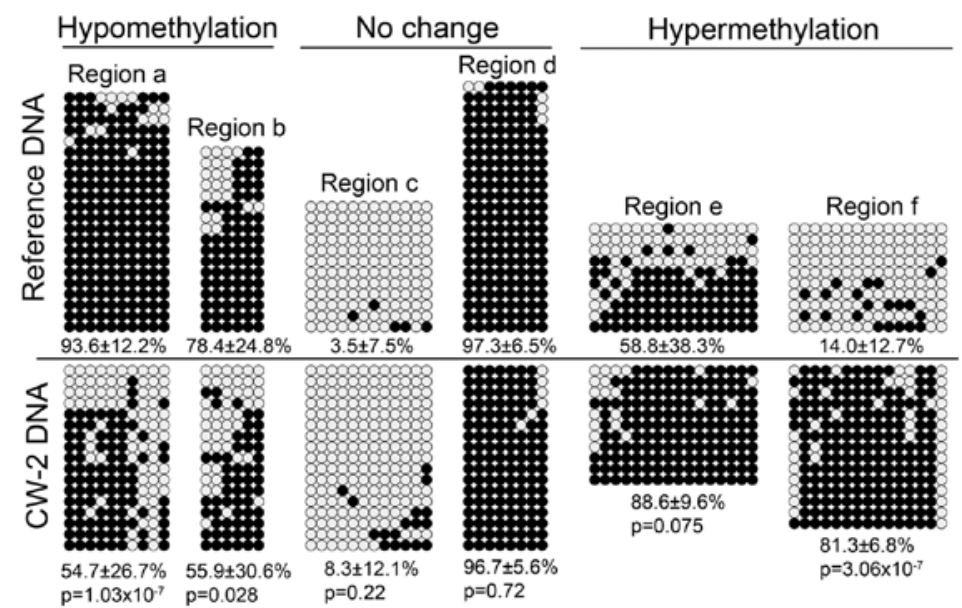

Figure 1. Logarithmic scatterplots of the self-self hybridization (a) and the CW-2 (b) MS-AFLP array experiments. In both graphs, the solid diagonal black line indicates the $\log 2$ ratio $=0$ (no change). The dashed lines indicate $\log 2$ ratio $=1$ and $\log 2$ ratio $=-1$, used as thresholds for hypomethylation and hypermethylation cells, respectively. Six spots were selected from the CW-2 MS-AFLP array: two hypomethylated (spots a and b), two with no change (spots c and d) and two hypermethylated (spots e and f). The methylation of the NotI sites associated to these spots was analyzed by bisulfite sequencing (c). Every row of circles represents the sequence of an individual clone. Black circles represent metyhylated CpG sites while white circles represent unmethylated CpG sites. For every region, the methylation fraction was calculated by averaging the methylation level of every individual clone. Statistical significance of the methylation fraction differences was analyzed by Wilcoxon rank sum test.

a very strong association between the presence of mononucleotide repeats in the probe sequences and the reduction in their signal intensity in the CW-2 sample, resulting in a negative $\log 2$ ratio $\left(\mathrm{OR}=6.6,95 \% \mathrm{CI}=3.6-11.5, \mathrm{P}=1.3 \times 10^{-8}\right.$ Fisher's exact test). While the possibility that some of these probes indicate actual methylation alterations can not be discarded, it seems more plausible that the reduction of signal intensity is a consequence of microsatellite shortenings and expansions in the genome of CW-2 cells, resulting in loss of perfect complementarity between the MS-AFLP amplicons and the MS-AFLP array probes. Therefore, to avoid miss-interpretation errors, polyN-containing probes were not considered for the scoring of alterations in the subsequent analysis of CW-2 MS-AFLP array. Of the remaining 13,395 probes, $482(3.6 \%)$ indicated hypermethylation and 128 $(0.96 \%)$ indicated hypomethylation.

The majority of the alterations were detected by probes mapping in a single location $(558 / 610,91.5 \%)$ or in 2-10 locations $(47 / 610,7.7 \%)$. Only five of the altered probes mapped in $>10$ locations in the genome, all of them within repetitive sequences (data not shown). We also investigated whether DNA methylation alterations were more frequently detected in NotI sites located close to gene transcriptional start sites (TSS), where presumably these alterations might be associated to transcriptional variations. Since the TSS is not well defined for all the annotated human genes, we considered a promoter-containing region the $10-\mathrm{kb}$ region surrounding the annotated $5^{\prime}$ end of the genes $(5 \mathrm{~kb}$ upstream and $5 \mathrm{~kb}$ downstream). In CW-2, both hypermethylation and hypomethylation alterations were actually more frequent in the NotI sites located outside of these promoter-related regions. The negative association of hypermethylation alterations with the $5^{\prime}$ regions exhibited an odds ratio (OR) of $0.80(95 \% \mathrm{CI}$ 0.66-0.96, $\mathrm{P}=0.018$ Fisher's exact test). The negative association of hypomethylation alterations with the 5 ' regions exhibited an $\mathrm{OR}=0.62(95 \%$ CI $0.43-0.89, \mathrm{P}=0.008)$. This observation is in agreement with recent findings showing that in colon cancer most DNA methylation alterations occur not in promoters or in CpG islands, but in 'shore' sequences up to $2 \mathrm{~kb}$ distant (25). A list of the NotI sites with methylation alterations in CW-2, their genomic location, and the associated genes is available upon request. 
Table I. Patient and tissue characteristics, and epigenetic alterations.

\begin{tabular}{|c|c|c|c|c|c|c|c|}
\hline \multirow[b]{2}{*}{ Patient } & \multirow[b]{2}{*}{ Gender } & \multirow[b]{2}{*}{ Age } & \multirow[b]{2}{*}{ Disease duration } & \multirow[b]{2}{*}{ Matts' score ${ }^{a}$} & \multicolumn{3}{|c|}{ Methylation alterations ${ }^{\mathrm{b}}$} \\
\hline & & & & & Hyper & Hypo & Total \\
\hline UC. 1 & $\mathrm{~F}$ & 46 & 14 & 3.3 & $0.64 \%$ & $0.64 \%$ & $1.27 \%$ \\
\hline $\mathrm{UC} .2$ & $\mathrm{~F}$ & 67 & 13 & 3.3 & $0.41 \%$ & $0.14 \%$ & $0.55 \%$ \\
\hline UC. 3 & $\mathrm{~F}$ & 23 & 2 & 3.3 & $0.24 \%$ & $0.37 \%$ & $0.61 \%$ \\
\hline UC.4 & M & 37 & 12 & 3.7 & $0.66 \%$ & $0.31 \%$ & $0.97 \%$ \\
\hline UC.5 & $\mathrm{M}$ & 56 & 5 & 2.3 & $1.07 \%$ & $0.64 \%$ & $1.71 \%$ \\
\hline UC.6 & M & 28 & 10 & 2.7 & $0.48 \%$ & $0.46 \%$ & $0.94 \%$ \\
\hline UC.7 & M & 36 & 16 & 1.3 & $0.23 \%$ & $0.61 \%$ & $0.84 \%$ \\
\hline UC.8 & M & 19 & 1.5 & 2.7 & $0.97 \%$ & $1.02 \%$ & $1.99 \%$ \\
\hline UC.9 & $\mathrm{M}$ & 42 & 10 & 2 & $0.82 \%$ & $0.68 \%$ & $1.50 \%$ \\
\hline UC.10 & M & 26 & 6 & 1.7 & $1.12 \%$ & $0.72 \%$ & $1.83 \%$ \\
\hline UC.11 & $\mathrm{F}$ & 43 & 3 & 2.3 & $0.98 \%$ & $0.50 \%$ & $1.48 \%$ \\
\hline UC.12 & $\mathrm{F}$ & 23 & 9 & 2.3 & $1.04 \%$ & $0.34 \%$ & $1.38 \%$ \\
\hline UC.13 & $\mathrm{F}$ & 32 & -9 & 3 & $0.87 \%$ & $0.80 \%$ & $1.67 \%$ \\
\hline UC.14 & $\mathrm{M}$ & 35 & 10 & 2.7 & $0.42 \%$ & $0.38 \%$ & $0.81 \%$ \\
\hline Mean \pm SD & $\begin{array}{c}57 \% \mathrm{M} \\
43 \% \mathrm{~F}\end{array}$ & $36.6 \pm 13.4$ & $8.6 \pm 4.5$ & $2.6 \pm 0.7$ & $0.7 \pm 0.3 \%$ & $0.5 \pm 0.2 \%$ & $1.3 \pm 0.5 \%$ \\
\hline
\end{tabular}

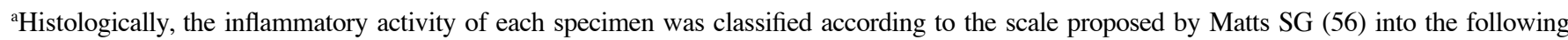
categories: grade 1 (no inflammation), grade 2 (mild inflammation), grade 3 (moderate inflammation), grade 4 (severe inflammation). ${ }^{\text {bercent }}$ of the MS-AFLP array spots that passed the low-intensity filter (13,515 per array) and exhibited $\log 2$ ratios below the hypermethylation threshold (hyper) or above the hypomethylation threshold (hypo). The total refers to the sum of hypermethylation and hypomethylation alterations.

Using the database for annotation, visualization and integrated discovery v6.7 (DAVID) $(33,34)$ we analyzed the enrichment of gene families among the hypermethylated or hypomethylated genes versus the list of genes present in the array. For hypermethylation, this analysis revealed a highly significant overrepresentation of genes encoding transcriptional factors (GOterm 0003700, $\mathrm{n}=49$, fold enrichment, 1.86; EASE score, $\left.1.14 \times 10^{-5}\right)$, in particular, transcriptional factors with homeobox domains (Interpro IPR001356, $\mathrm{n}=25$, fold enrichment, 3.32; EASE score, $1.9 \times 10^{-7}$ ). In addition, forty-two of the hypermethylated genes are involved in developmental processes

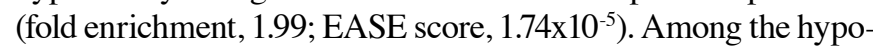
methylated genes, we found an enrichment of genes involved in epithelial cell development (GO term 0060429, $n=6$, fold enrichment, 4.37; EASE score, 0.01).

DNA methylation alterations in the colonic mucosa of UC patients. Once the MS-AFLP array was validated in the CW-2 colorectal cancer cell line, we analyzed 14 colonic mucosa samples obtained from UC patients (UCM). Table I shows the clinicopathological features of the patients recruited in this study and the frequency of DNA methylation alterations detected by the MS-AFLP array analyses. No association was found between patient age, duration of disease or inflammation grade and the incidence of methylation alterations. The analysis of the data from all the UCM samples together revealed a negative association between methylation alterations and the 5 ' region of genes $(\mathrm{OR}=0.84, \mathrm{P}=0.0013,95 \% \mathrm{CI} 0.75-0.93$ for hypermethylation, and $\mathrm{OR}=0.78, \mathrm{P}=7.5 \times 10^{-5}, 95 \% \mathrm{CI}=0.69-0.88$ for hypomethylation. Fisher's exact test).

Identification of frequently altered loci. To identify the probes altered in the UCM samples with a statistically significant frequency, we applied a binomial test based on the frequency of alterations empirically obtained from every individual sample, under the null hypothesis that every probe had the same probability of being altered within a sample. The level of statistical significance was set at $\mathrm{P}<0.01$ after correction for multi-hypothesis testing by the Holm method (31). Results are shown in Fig. 2. This analysis rendered 133 probes indicating hypermethylation in 3-12 of the 14 samples (frequently hypermethylated set), and 118 probes indicating hypomethylation in 3-14 of the 14 samples (frequently hypomethylated set). Twelve probes were common to both hypermethylated and hypomethylated sets, that is, hypermethylated in three or more samples and hypomethylated in three or more different samples.

The frequently hypermethylated probe set was enriched in genes participating in transcriptional processes, i.e., encoding transcriptional factors and transcriptional modulators and proteins with RNA-binding function, and genes involved in signal transduction, such as protein kinases and $\mathrm{SH} 2$ domaincontaining proteins (data not shown). Interestingly, the second most frequently hypermethylated probe is located in the promoter of MPG, a gene that codes for the N-methylpurine-DNA glycosylase involved in the repair of DNA alkylation lesions caused by reactive oxygen and nitrogen species (RONS), which are 

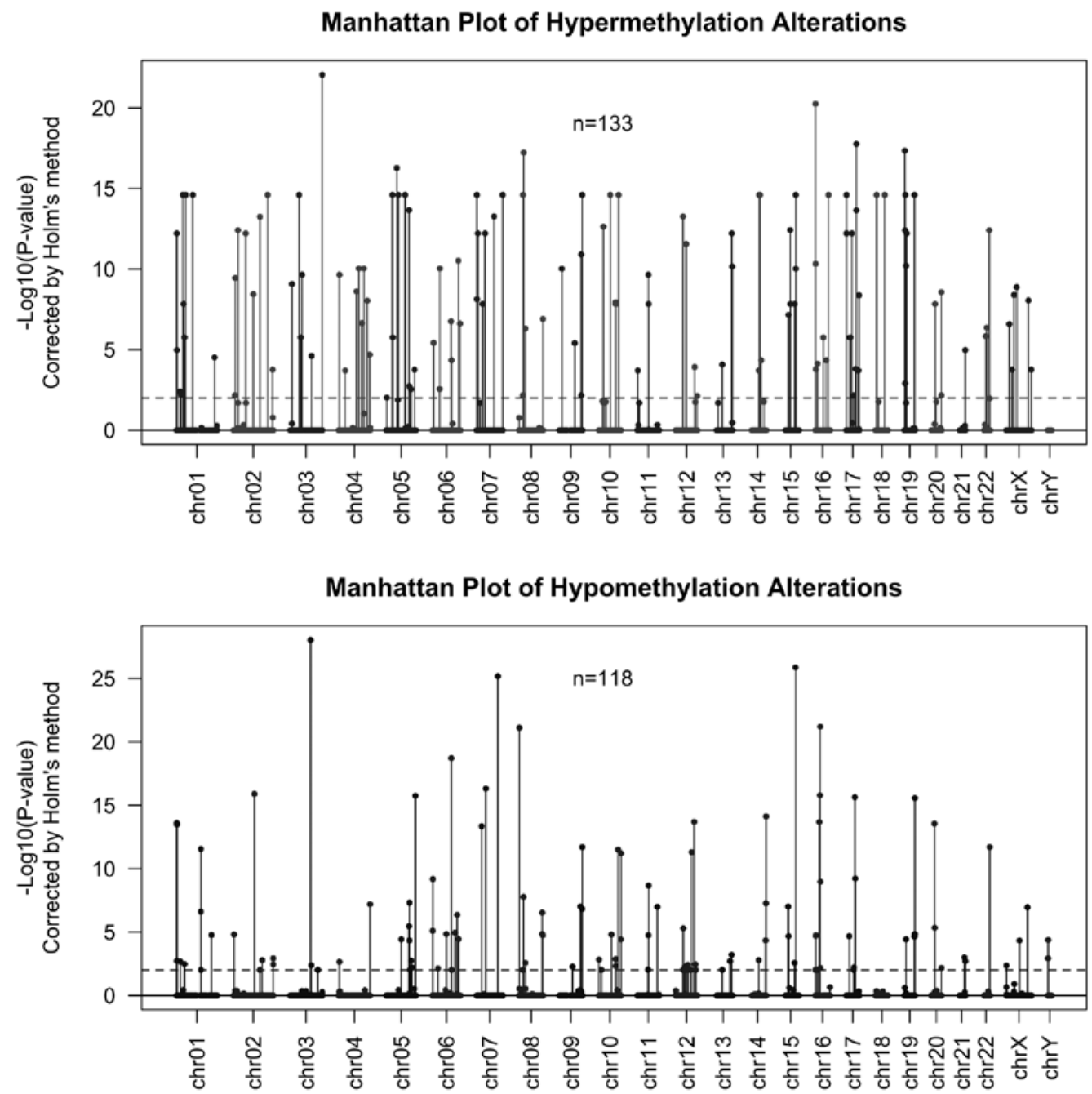

Figure 2. Manhattan plots of the frequency of hypermethylation alterations (upper graph) and the frequency of hypomethylation alterations (lower graph) in the 14 analyzed UC samples. The p-values were calculated by a binomial test based on the frequency of alterations empirically obtained from every individual sample, under the null hypothesis that every probe had the same probability of being altered within a sample. P-values were subsequently corrected for multihypothesis testing by Holm's method. The dashed horizontal line represents the applied statistical significance level, set at $\mathrm{P}=0.01$.

typical products of the chronic inflammation process. In addition, six of the frequently hypermethylated genes, i.e., CCND1, COL4A2, HDAC2, AXIN2, ABL1 and GLI2, are included in the pathways in cancer map from the KEGG database (37).

Hypomethylation associates with repetitive elements. In comparison with the frequently hypermethylated probe set, the gene enrichment analysis of the frequently hypomethylated probe set revealed a lower number of highly-significant gene categories. Of note, we found a borderline significant enrichment of genes with protein kinase C-like domains (RASGRP1, CDC42BPB and PRKCB; EASE score, 0.14; Fisher's exact test $\mathrm{P}=0.016$ ). Two of these genes, RASGRP1 and PRKCB, function as positive regulators of the Ras signaling pathway. The analysis also revealed a significant enrichment (fold enrichment, 8.0; EASE score, 0.05; Fisher's exact test $\mathrm{P}=0.006$ ) of genes associated with cell differentiation (NOG, FOXC1 and HNRNPAB).

Among the 118 frequently hypomethylated probes, seven were complementary to high copy number elements, revealing a strong association between hypomethylation and DNA repetitive elements $\left(\mathrm{OR}=6.3 ; 95 \% \mathrm{CI} 2.4-13.7 ; \mathrm{P}=2.1 \times 10^{-4}\right.$, Fisher's exact test). A more extensive analysis of the 196 MS-AFLP array probes complementary to high-copy repetitive elements ( $>100$ hits in the genome) revealed that more than half of the samples (8 out of 14) showed hypomethylation in at least one of the probes located in Alu repetitive elements. In contrast, none of these 196 probes indicated hypermethylation in any of the 14 analyzed cases. Demethylation of repetitive elements is a generally accepted surrogate of global DNA hypomethylation (26). Hence, this finding is in agreement with previous reports that global genome-wide demethylation is a common phenomenon in the inflamed colonic mucosa of UC patients (19).

Clustering of altered loci in the colonic mucosa of UC patients. We performed a Euclidean distance unsupervised cluster analysis with the data from all the probes hypermethylated in 2 or more samples or hypomethylated in 2 or more samples (Fig. 3). This analysis revealed 5 main gene clusters, named A-E, and three distinct groups of samples that were primarily defined by differences in the methylation status of three of these gene clusters (A, B and D). Clusters C and E were mainly hypermethylated and hypomethylated, respectively, in all the samples and 


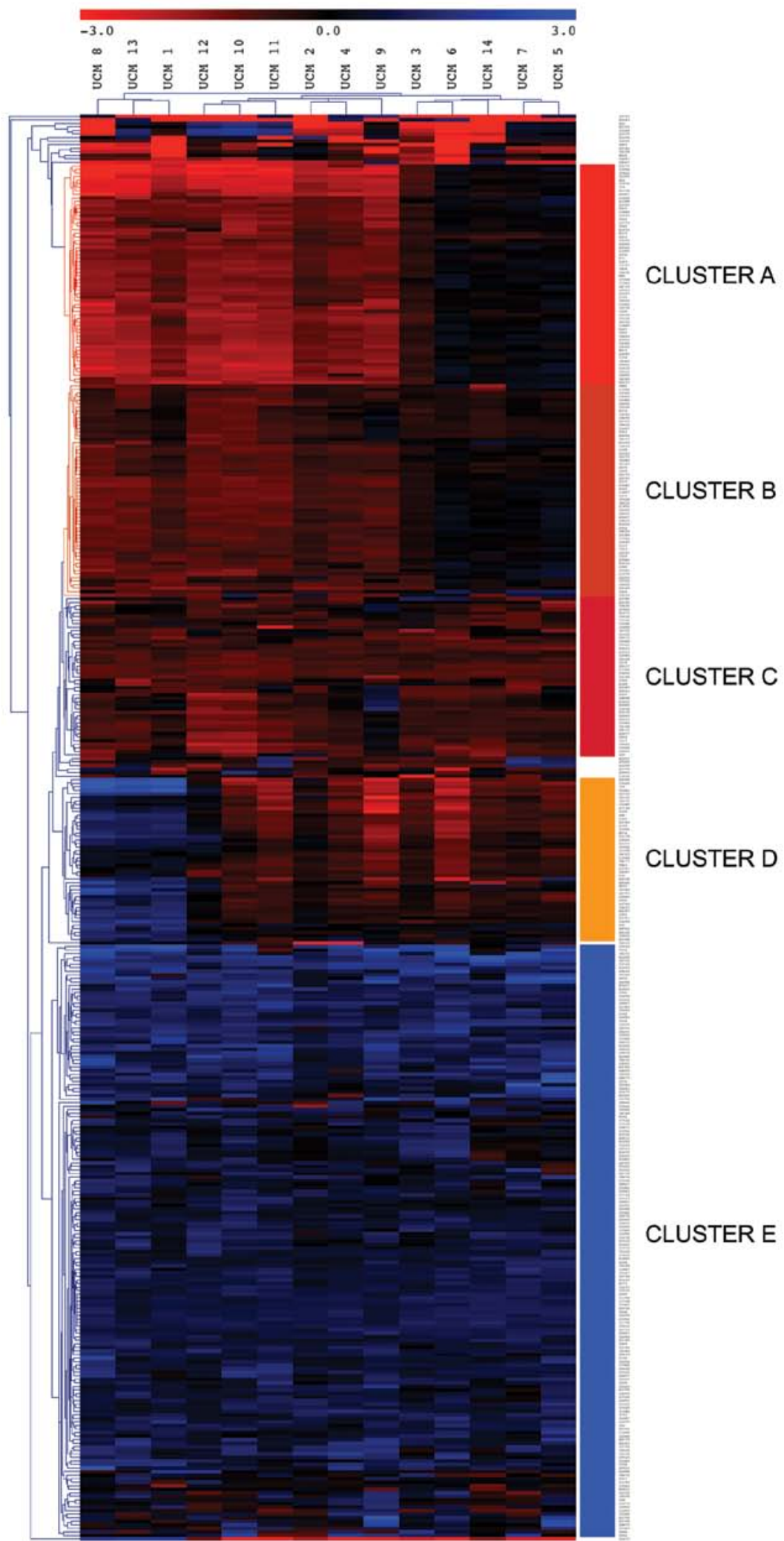

Figure 3. Heatmap of the methylation alterations detected by the MS-AFLP arrays. Only alterations detected in two or more of the UC samples are included in the figure. Red indicates hypermethylation $(\log 2$ ratio $<-1)$ and blue indicates hypomethylation $(\log 2$ ratio $>1)$. Every column corresponds to a different sample, and every row corresponds to a different MS-AFLP array spot. Cases and spots were clustered according to the Euclidean distance using MeV. The analysis revealed 5 main spot clusters (A-E). Samples were classified in three main groups based on the methylation status of the clusters A, B and D. For more information about the genes in each cluster, see the main text.

exhibited lower classification power. The clustering revealed three distinctive groups of patients. A group of three cases (samples 1, 8 and 13, left of the heatmap) was characterized by strong hypermethylation of cluster $\mathrm{A}$, and hypomethylation of cluster D. A second group of 6 patients (samples 2, 4, 9, 10, 11 and 12 , center of the heatmap) showed hypermethylation in all 
Table II. Concordance between hypermethylation and hypomethylation alterations detected by MS-AFLP arrays in cancer cell line CW-2 and non-cancer UCM samples.

A, Hypermethylation alterations

In UCM

\begin{tabular}{cr}
\hline $\begin{array}{c}\text { Hyper- } \\
\text { methylated }^{\mathrm{a}}\end{array}$ & $\begin{array}{c}\text { Non-hyper- } \\
\text { methylated }\end{array}$
\end{tabular}

\section{In CW-2}

$\begin{array}{lcc}\text { Hypermethylated } & 62 & 421 \\ \text { Non-hypermethylated } & 86 & 12946 \\ & \text { Odds ratio }=22.15 \\ & 95 \% \text { CI 15.48-31.56 } \\ & \text { Fisher's exact test } \mathrm{P}<2.2 \times 10^{-16}\end{array}$

B, Hypomethylation alterations

In UCM

\begin{tabular}{cc}
\hline $\begin{array}{c}\text { Hyper- } \\
\text { methylated }^{\mathrm{b}}\end{array}$ & $\begin{array}{c}\text { No hyper- } \\
\text { methylated }\end{array}$
\end{tabular}

\section{In CW-2}

$\begin{array}{lcc}\text { Hypomethylated } & 27 & 102 \\ \text { Non-hypomethylated } & 91 & 13295 \\ & \text { Odds ratio }=38.63 \\ & 95 \% \text { CI 23.13-62.91 } \\ & \text { Fisher's exact test } \mathrm{P}<2.2 \times 10^{-16}\end{array}$

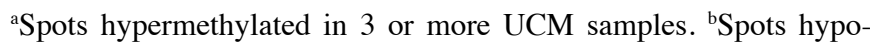
methylated in 3 or more UCM samples. The total number of spots is 13,515 after filtering the $30 \%$ lowest-intensity spots from the 19,308 methylation-sensitive spots printed on the MS-AFLP array. The number of spots without changes is an over-estimation because they include other loci that were not sufficiently amplified in the respective experiments.

clusters, but cluster E. Finally, a group of 5 patients (samples 3 , $5,6,7$ and 14, right of the heatmap) exhibited a characteristic absence of hypermethylation in clusters A and B. No obvious differences were found among the three groups of patients regarding age, gender, degree of inflammation or duration of the disease. A list of the Not I sites with DNA methylation alterations in these UCM samples, their genomic location, and the associated genes is available upon request.

Concordance of epigenetic alterations in non-cancer colonic mucosa of UC patients and CW-2 colon cancer cells. We compared the alterations in NotI sites observed in the UCM samples with those identified in the previous analysis of the $\mathrm{CW}-2$ cancer cell line. There was a strong concordance between the alterations found in the UCM samples and those found in the CW-2 cell line, both for hypermethylation and hypomethylation alterations (Table II). The detailed gene-enrichment and gene ontology analysis of these data will be published elsewhere.

\section{Discussion}

We described a novel microarray-based platform, termed MS-AFLP array, designed to analyze DNA methylation alterations in the nearly 10,000 NotI sites of the human genome. This platform is based on the robust MS-AFLP technique (20) that we previously employed to show that DNA methylation alterations are gradual and that hypomethylation appears to be dominant over hypermethylation in linking epigenotype with cancer genotype and clinical outcome in sporadic gastrointestinal cancers $(22,23)$. Our platform possesses some unique characteristics compared to other methylation microarrays platforms. Most notably, it does not rely on the treatment of DNA with bisulfite (30). Instead, the DNA samples are digested with a combination of one methylation-sensitive (NotI) and one methylation-insensitive ( $\mathrm{Mse}$ I) restriction enzymes, then adaptors are ligated and the fragments are amplified by PCR. Thus, the genomic distribution of probes is dictated by the distribution of Not I sites, which are located not only in promoter regions but also in intra- and intergenic regions.

We tested the platform in the colorectal cancer cell line CW-2, and showed the ability and accuracy of the MS-AFLP array to detect DNA methylation alterations (Fig. 1). Hypermethylated probes (482) were almost 5 times more frequent than the hypomethylated (128) probes. This finding might seem counterintuitive, since DNA hypomethylation, the almost constant companion to DNA hypermethylation in cancer, preferentially occurs in repetitive elements such as LINE-1 and Alu sequences that account for $34 \%$ of the human genome, while hypermethylation generally occurs in unique sequences, so the combined effect of these two types of alterations is an overall loss of DNA methylation. In the CW-2 MS-AFLP array context, however, it must be noted that: a) the vast majority of NotI sites lay not in LINE-1 or Alu elements but in unique loci, and therefore the detection is biased towards alterations occurring in single-copy elements, and b) CW-2 cells exhibit a particularly high level of global DNA methylation. In fact, this cell line ranks third in terms of LINE-1 methylation levels when compared to a panel of 13 colorectal cancer cell lines, only surpassed by the heavily methylated cell lines HCT116 and SW48 (38). The high level of hypermethylation of the CW-2 cells, however, does not seem to be attributed to the reported elevated level of hypermethylation of sporadic MSI colon cancer (39) because the cells contain a double mutation of MLH1 (a nonsense mutation fixed in homozygosis by copy neutral LOH) rather than its epigenetic silencing by hypermethylation.

Hypermethylation alterations in the tumor cell line were strongly associated to genes encoding transcriptional factors (fold enrichment, 1.86; EASE score, $1.14 \times 10^{-5}$ ). The epigenetic silencing of transcriptional factors likely reflects a dramatic epigenetic reprogramming that globally alters the gene expression profile of the cancer cell. Many of these changes are probably associated to the malignant transformation of the primary tumor from which this cell line is derived rather than to the subsequent in vitro culturing conditions of CW-2 cells (40). This conclusion is based on the similarity of the findings between this tumor cell line and results with primary colon cancers (data not shown). 
For instance, the subgroup of transcription factors exhibiting the highest statistical significant over-representation comprised the homeobox-containing genes (IPR: IPR001356, fold enrichment, 3.32; EASE score, $2.95 \times 10^{-8}$ ). This result confirms our previous finding, back in 1999, by MS-AFLP fingerprinting, that the homeobox-containing genes are preferential targets of methylation alterations in colon cancer (41), later confirmed by other groups (42-44).

A possible mechanism underlying the association between homeobox-containing genes and aberrant hypermethylation has been proposed recently. The two main cell memory systems involved in the maintenance of a stem cell state, i.e., the Trithorax (Trx) and Polycomb repressor complexes (PRCs), have been suggested to participate in the aberrant DNA hypermethylation found in colorectal cancers (45-47). It has been found that PRC-target genes, including the Hox gene clusters, are up to 12-fold more likely to have cancer-specific promoter DNA hypermethylation than non-targets (47) and that methylation on Lys 27 of histone $\mathrm{H} 3$, a modification mediated by the Polycomb repressor complex 2 (PRC2), pre-marks genes for de novo methylation in cancer (46). This proposed mechanism, however, is insufficient to explain all the hypermethylation alterations observed in colorectal cancer cells, because many of the frequently altered genes are not polycomb targets. For instance, $h M L H 1$, hypermethylated in the majority of sporadic MSI colorectal cancers and classified as one of the targets of the so-called CIMP (CpG island methylator phenotype) (39). Hence, the mechanisms that drive aberrant hypermethylation in cancer remains to date to be explained.

Among the hypomethylated loci, the most significant also were transcription factors involved in epithelium cell differentiation or proliferation, secreted proteins and proteins involved in acetylation. Of note, several homeobox-containing genes were also identified as hypomethylated (HOXB5, PHOX2A and HLX), indicating that these genes are under epigenetic regulation other than DNA hypermethylation.

In the second phase of this study, we employed the MS-AFLP array to study methylation alterations in the non-cancer colonic mucosa of UC patients. Overall, hypermethylated probes were also slightly more abundant that hypomethylated probes (difference, $0.17 \pm 0.29 \% ; \mathrm{P}=0.047$, exact Wilcoxon signed rank test), but whereas hypermethylation occurred exclusively in unique or very low copy number sequences, hypomethylation exhibited a very strong positive association with highly repeated DNA elements, in particular with Alu repetitive elements which have been shown to undergo demethylation in colorectal cancer (48). Hence, this result supports the previous observation that global DNA hypomethylation is a common phenomenon in UC colonic mucosa (19), and shows a link between chronic inflammation and cancer in UC patients and accumulative demethylation of Alu repetitive elements $(26,48)$.

We ranked the alterations based on their incidence, and then applied a strict threshold $(\mathrm{P}<0.01)$ to identify those exhibiting an incidence above the random chance. This analysis rendered 133 probes hypermethylated in 3-12 samples, associated to 111 genes, and 118 probes hypomethylated in 3-14 samples and associated to 93 genes (Fig. 2).

A significant number of the hypermethylated genes encode transcriptional factors and chromatin remodelers (KLF7,
SLC2A4RG, TBX2, IRX2, GLI2, SOX8, YBX1, GABPB1, HDAC2, SIX1, RFX1, MKX, FOXD2, RUNX2, TLX2, TLX1), some already reported to be associated to colon cancer (49-51). Five of these transcriptional factors (IRX2, SIX1, MKX, TLX2, TLX1) contain a homeobox domain. In addition, there were alterations in genes that might contribute to the deregulation of cancer-associated signaling pathways. For instance, we found frequent hypermethylation of two probes corresponding to one NotI site located in the gene body of AXIN2. AXIN2 acts as negative regulator of canonical Wnt signaling pathway by enhancing the recruitment of the $\beta$-catenin degradation complex. Inactivating mutations and epigenetic silencing of AXIN2 have been previously reported to be involved in MSI colorectal cancer $(52,53)$, mainly by deregulating the Wnt signaling pathway. The MS-AFLP array analysis also revealed epigenetic alterations in other members of the Wnt (WNT2, WNT3, WNT3A, WNT6 and WNT10B) and MAPK (CACNG8, EGFR, HSPA8, IKBKB, MAP2K3, PPP3CC, PRKCB RASGRP1, RRAS2 and TAB1) signaling pathways. In total, twenty-two of the frequently altered genes (ABL1, AXIN2, CCND1, COL4A2, DAPK3, EGFR, EPAS1, FLT3, GLI2, HDAC2, IKBKB, JUP, LAMA1, MSH6, PRKCB, PTEN, RUNX1T1, WNT10B, WNT2, WNT3, WNT3A, WNT6) belong to the pathways in cancer KEGG map (hsa05200). In addition, we found very frequent (78.6\%) hypermethylation of the promoter region of MPG, a gene that encodes an alkylpurine DNA glycosylase responsible for the reparation of alkylated adenines and guanines. This type of DNA lesion can be caused from inflammation-associated reactive oxygen and nitrogen species (RONS). A recent study demonstrated that mice deficient for the murine MPG-homologous gene, i.e., Aag, accumulate more DNA lesions after dextran sulfate-induced colonic inflammation and are more susceptible to colon tumorigenesis (54). Hence, the finding of epigenetic alterations in MPG in UC patients suggests that the colonic mucosa of these patients are not only more exposed to the deleterious effect of the RONS generated by the inflammatory response, but also that they might suffer the impairment of the alkylated-DNA reparation mechanism, thus exacerbating the effect of these mutagens. We also found hypermethylation of the probe associated to the gene BOP1 in $36 \%$ of the UCM samples. This gene has been suggested to contribute to colorectal tumorigenesis by deregulating chromosomal segregation (55).

The concordance between many loci altered in the UCM samples and the cancer cells from the CW-2 cell line (Table II) indicates that the epithelial cells of the colonic mucosa of UC patients have undergone a number of epigenetic alterations shared with colon cancer cells. Therefore, some of these epigenetic changes may be useful as surrogate biomarkers for prediction of colon cancer development in normal colonic mucosa.

In conclusion, to the best of our knowledge, this work presents the first genomic DNA methylation profile underlying ulcerative colitis. Many of these alterations occur in genes that participate in well-established oncogenic pathways and are shared with fully malignant cells. Thus, our data support the concept of an epigenetic field for cancerization associated to the long-term risk for carcinogenesis in UC patients, by the accumulation of epigenetic alterations, followed by genetic alterations, that persist after the inflammation is treated and predispose the epithelial cells to progress into malignancy. 


\section{Acknowledgements}

This work was supported in part by a grant-in-aid for postgraduate students from Jichi Medical University and by grant PI09/02444 from the Fondo de Investigación Sanitarias (FIS) from the Instituto de Salud Carlos III, Ministry of Science and Innovation, Spain. Toshiki Taya is an employee of Agilent Technologies.

\section{References}

1. Lashner BA, Silverstein MD and Hanauer SB: Hazard rates for dysplasia and cancer in ulcerative colitis. Results from a surveillance program. Dig Dis Sci 34: 1536-1541, 1989.

2. Ekbom A, Helmick C, Zack M and Adami HO: Ulcerative colitis and colorectal cancer. A population-based study. N Engl J Med 323: 1228-1233, 1990.

3. Eaden JA, Abrams KR and Mayberry JF: The risk of colorectal cancer in ulcerative colitis: a meta-analysis. Gut 48: 526-535, 2001

4. Itzkowitz SH and Present DH: Consensus conference: colorectal cancer screening and surveillance in inflammatory bowel disease. Inflamm Bowel Dis 11: 314-321, 2005.

5. Pohl C, Hombach A and Kruis W: Chronic inflammatory bowel disease and cancer. Hepatogastroenterology 47: 57-70, 2000.

6. Geboes K: Ulcerative colitis and malignancy. Acta Gastroenterol Belg 63: 279-283, 2000.

7. Provenzale D and Onken J: Surveillance issues in inflammatory bowel disease: ulcerative colitis. J Clin Gastroenterol 32: 99-105, 2001.

8. Itzkowitz SH and Yio X: Inflammation and cancer IV. Colorectal cancer in inflammatory bowel disease: the role of inflammation. Am J Physiol Gastrointest Liver Physiol 287: G7-G17, 2004.

9. Garrity-Park MM, Loftus EV Jr, Sandborn WJ, Bryant SC and Smyrk TC: Methylation status of genes in non-neoplastic mucosa from patients with ulcerative colitis-associated colorectal cancer. Am J Gastroenterol 105: 1610-1619, 2010.

10. Issa JP: CpG-island methylation in aging and cancer. Curr Top Microbiol Immunol 249: 101-118, 2000.

11. Maekita T, Nakazawa K, Mihara M, Nakajima T, Yanaoka K, Iguchi M, Arii K, Kaneda A, Tsukamoto T, Tatematsu M, Tamura G, Saito D, Sugimura T, Ichinose $M$ and Ushijima T: High levels of aberrant DNA methylation in Helicobacter pyloriinfected gastric mucosae and its possible association with gastric cancer risk. Clin Cancer Res 12: 989-995, 2006.

12. Nakajima T, Maekita T, Oda I, Gotoda T, Yamamoto S, Umemura S, Ichinose $M$, Sugimura T, Ushijima $T$ and Saito D Higher methylation levels in gastric mucosae significantly correlate with higher risk of gastric cancers. Cancer Epidemiol Biomarkers Prev 15: 2317-2321, 2006.

13. Kondo Y, Kanai Y, Sakamoto M, Mizokami M, Ueda R and Hirohashi S: Genetic instability and aberrant DNA methylation in chronic hepatitis and cirrhosis: a comprehensive study of loss of heterozygosity and microsatellite instability at 39 loci and DNA hypermethylation on $8 \mathrm{CpG}$ islands in microdissected specimens from patients with hepatocellular carcinoma. Hepatology 32 : 970-979, 2000.

14. Ushijima T: Epigenetic field for cancerization. J Biochem Mol Biol 40: 142-150, 2007.

15. Hsieh CJ, Klump B, Holzmann K, Borchard F, Gregor M and Porschen R: Hypermethylation of the $\mathrm{p} 16^{\text {INK4a }}$ promoter in colectomy specimens of patients with long-standing and extensive ulcerative colitis. Cancer Res 58: 3942-3945, 1998.

16. Sato F, Harpaz N, Shibata D, Xu Y, Yin J, Mori Y, Zou TT, Wang S, Desai K, Leytin A, Selaru FM, Abraham JM and Meltzer SJ: Hypermethylation of the p14(ARF) gene in ulcerative colitisassociated colorectal carcinogenesis. Cancer Res 62: 1148-1151, 2002.

17. Issa JP, Ahuja N, Toyota M, Bronner MP and Brentnall TA: Accelerated age-related $\mathrm{CpG}$ island methylation in ulcerative colitis. Cancer Res 61: 3573-3577, 2001.

18. Fujii S, Tominaga K, Kitajima K, Takeda J, Kusaka T, Fujita M, Ichikawa K, Tomita S, Ohkura Y, Ono Y, Imura J, Chiba T and Fujimori T: Methylation of the oestrogen receptor gene in nonneoplastic epithelium as a marker of colorectal neoplasia risk in long-standing and extensive ulcerative colitis. Gut 54: 1287-1292, 2005 .
19. Gloria L, Cravo M, Pinto A, De Sousa LS, Chaves P, Leitao CN, Quina M, Mira FC and Soares J: DNA hypomethylation and proliferative activity are increased in the rectal mucosa of patients with long-standing ulcerative colitis. Cancer 78: 2300-2306, 1996.

20. Yamamoto F, Yamamoto M, Soto JL, Kojima E, Wang EN, Perucho M, Sekiya T and Yamanaka H: Notl-Msell methylationsensitive amplied fragment length polymorhism for DNA methylation analysis of human cancers. Electrophoresis 22: 1946-1956, 2001

21. Samuelsson JK, Alonso S, Yamamoto $F$ and Perucho $M$ : DNA fingerprinting techniques for the analysis of genetic and epigenetic alterations in colorectal cancer. Mutat Res 693: 61-76, 2010.

22. Yamashita K, Dai T, Dai Y, Yamamoto F and Perucho M: Genetics supersedes epigenetics in colon cancer phenotype. Cancer Cell 4: 121-131, 2003.

23. Suzuki K, Suzuki I,Leodolter A, Alonso S, Horiuchi S, Yamashita K and Perucho M: Global DNA demethylation in gastrointestinal cancer is age dependent and precedes genomic damage. Cancer Cell 9: 199-207, 2006.

24. Kageyama S, Shinmura K, Yamamoto H, Goto M, Suzuki K, Tanioka F, Tsuneyoshi T and Sugimura H: Fluorescence-labeled methylation-sensitive amplified fragment length polymorphism (FL-MS-AFLP) analysis for quantitative determination of DNA methylation and demethylation status. Jpn J Clin Oncol 38: 317-322, 2008.

25. Irizarry RA, Ladd-Acosta C, Wen B, Wu Z, Montano C, Onyango P, Cui H, Gabo K, Rongione M, Webster M, Ji H, Potash JB, Sabunciyan S and Feinberg AP: The human colon cancer methylome shows similar hypo- and hypermethylation at conserved tissue-specific $\mathrm{CpG}$ island shores. Nat Genet 41: 178-186, 2009.

26. Ehrlich M: DNA methylation in cancer: too much, but also too little. Oncogene 21: 5400-5413, 2002.

27. Yamamoto F and Yamamoto M: A DNA microarray-based methylation-sensitive (MS)-AFLP hybridization method for genetic and epigenetic analyses. Mol Genet Genomics 271: 678-686, 2004.

28. Rouillard JM, Zuker M and Gulari E: OligoArray 2.0: design of oligonucleotide probes for DNA microarrays using a thermodynamic approach. Nucleic Acids Res 31: 3057-3062, 2003.

29. Team RDC: R: A language and environment for statistical computing. R Foundation for Statistical Computing, Vienna, 2009.

30. Frommer M, McDonald LE, Millar DS, Collis CM, Watt F, Grigg GW, Molloy PL and Paul CL: A genomic sequencing protocol that yields a positive display of 5-methylcytosine residues in individual DNA strands. Proc Natl Acad Sci USA 89: 1827-1831, 1992.

31. Holm S: A simple sequentially rejective multiple test procedure. Scand J Statist 6: 65-70, 1979.

32. Saeed AI, Sharov V, White J, Li J, Liang W, Bhagabati N, Braisted J, Klapa M, Currier T, Thiagarajan M, Sturn A, Snuffin M, Rezantsev A, Popov D, Ryltsov A, Kostukovich E, Borisovsky I, Liu Z, Vinsavich A, Trush V and Quackenbush J: TM4: a free, open-source system for microarray data management and analysis. Biotechniques 34: 374-378, 2003.

33. Huang da W, Sherman BT and Lempicki RA: Systematic and integrative analysis of large gene lists using DAVID bioinformatics resources. Nat Protoc 4: 44-57, 2009.

34. Huang da W, Sherman BT, Tan Q, Kir J, Liu D, Bryant D, Guo Y, Stephens R, Baseler MW, Lane HC and Lempicki RA: DAVID Bioinformatics Resources: expanded annotation database and novel algorithms to better extract biology from large gene lists. Nucleic Acids Res 35: W169-W175, 2007.

35. Hosack DA, Dennis G Jr, Sherman BT, Lane HC and Lempicki RA: Identifying biological themes within lists of genes with EASE. Genome Biol 4: R70, 2003.

36. Ionov Y, Peinado MA, Malkhosyan S, Shibata D and Perucho M: Ubiquitous somatic mutations in simple repeated sequences reveal a new mechanism for colonic carcinogenesis. Nature 363: 558-561, 1993.

37. Kanehisa M and Goto S: KEGG: kyoto encyclopedia of genes and genomes. Nucleic Acids Res 28: 27-30, 2000.

38. Kawakami K, Matsunoki A, Kaneko M, Saito K, Watanabe G and Minamoto T: Long interspersed nuclear element-1 hypomethylation is a potential biomarker for the prediction of response to oral fluoropyrimidines in microsatellite stable and $\mathrm{CpG}$ island methylator phenotype-negative colorectal cancer. Cancer Sci 102: 166-174, 2011. 
39. Toyota M, Ahuja N, Ohe-Toyota M, Herman JG, Baylin SB and Issa JP: CpG island methylator phenotype in colorectal cancer. Proc Natl Acad Sci USA 96: 8681-8686, 1999.

40. Smiraglia DJ, Rush LJ, Fruhwald MC, Dai Z, Held WA, Costello JF, Lang JC, Eng C, Li B, Wright FA, Caligiuri MA and Plass C: Excessive $\mathrm{CpG}$ island hypermethylation in cancer cell lines versus primary human malignancies. Hum Mol Genet 10: 1413-1419, 2001.

41. Perucho M, Tokino T and Nakamura Y: Cancer genomics and molecular diagnosis - The Nineteenth International Symposium of Sapporo Cancer Seminar. Jpn J Cancer Res 90: 1273-1276, 1999.

42. Raman V, Martensen SA, Reisman D, Evron E, Odenwald WF, Jaffee E, Marks J and Sukumar S: Compromised HOXA5 function can limit p53 expression in human breast tumours. Nature 405 974-978, 2000.

43. Shiraishi M, Sekiguchi A, Oates AJ, Terry MJ and Miyamoto Y: HOX gene clusters are hotspots of de novo methylation in $\mathrm{CpG}$ islands of human lung adenocarcinomas. Oncogene 21: 3659-3662, 2002.

44. Shah N and Sukumar S: The Hox genes and their roles in oncogenesis. Nat Rev Cancer 10: 361-371, 2010.

45. Vire E, Brenner C, Deplus R, Blanchon L, Fraga M, Didelot C, Morey L, van Eynde A, Bernard D, Vanderwinden JM, Bollen M, Esteller M, Di Croce L, De Launoit Y and Fuks F: The Polycomb group protein EZH2 directly controls DNA methylation. Nature 439: 871-874, 2006.

46. Schlesinger Y, Straussman R, Keshet I, Farkash S, Hecht M, Zimmerman J, Eden E, Yakhini Z, Ben-Shushan E, Reubinoff BE, Bergman Y, Simon I and Cedar H: Polycomb-mediated methylation on Lys27 of histone H3 pre-marks genes for de novo methylation in cancer. Nat Genet 39: 232-236, 2007.

47. Widschwendter M, Fiegl H, Egle D, Mueller-Holzner E, Spizzo G, Marth C, Weisenberger DJ, Campan M, Young J, Jacobs I and Laird PW: Epigenetic stem cell signature in cancer. Nat Genet 39: 157-158, 2007.

48. Rodriguez J, Vives L, Jorda M, Morales C, Munoz M, Vendrell E and Peinado MA: Genome-wide tracking of unmethylated DNA Alu repeats in normal and cancer cells. Nucleic Acids Res 36: $770-784,2008$
49. Mazumdar T, De Vecchio J, Shi T, Jones J, Agyeman A and Houghton JA: Hedgehog signaling drives cellular survival in human colon carcinoma cells. Cancer Res 71: 1092-1102, 2011.

50. Hanigan CL, Van Engeland M, De Bruine AP, Wouters KA, Weijenberg MP, Eshleman JR and Herman JG: An inactivating mutation in HDAC2 leads to dysregulation of apoptosis mediated by APAF1. Gastroenterology 135: 1652-1664, 2008.

51. Slattery ML, Lundgreen A, Herrick JS, Caan BJ, Potter JD and Wolff RK: Associations between genetic variation in RUNX1, RUNX2, RUNX3, MAPK1 and eIF4E and riskof colon and rectal cancer: additional support for a TGF-beta-signaling pathway. Carcinogenesis 32: 318-326, 2011.

52. Koinuma K, Yamashita Y, Liu W, Hatanaka H, Kurashina K, Wada T, Takada S, Kaneda R, Choi YL, Fujiwara SI, Miyakura Y, Nagai H and Mano H: Epigenetic silencing of AXIN2 in colorectal carcinoma with microsatellite instability. Oncogene 25: 139-146, 2006.

53. Liu W, Dong X, Mai M, Seelan RS, Taniguchi K, Krishnadath KK, Halling KC,Cunningham JM,BoardmanLA, Qian C,ChristensenE, Schmidt SS, Roche PC, Smith DI and Thibodeau SN: Mutations in AXIN2 cause colorectal cancer with defective mismatch repair by activating beta-catenin/TCF signalling. Nat Genet 26: 146-147, 2000.

54. Meira LB, Bugni JM, Green SL, Lee CW, Pang B, Borenshtein D, Rickman BH, Rogers AB, Moroski-Erkul CA, McFaline JL, Schauer DB, Dedon PC, Fox JG and Samson LD: DNA damage induced by chronic inflammation contributes to colon carcinogenesis in mice. J Clin Invest 118: 2516-2525, 2008.

55. Killian A, Sarafan-Vasseur N, Sesboue R, Le Pessot F, Blanchard F, Lamy A, Laurent M, Flaman JM and Frebourg T: Contribution of the BOP1 gene, located on 8q24, to colorectal tumorigenesis. Genes Chromosomes Cancer 45: 874-881, 2006.

56. Matts SG: The value of rectal biopsy in the diagnosis of ulcerative colitis. Q J Med 30: 393-407, 1961. 